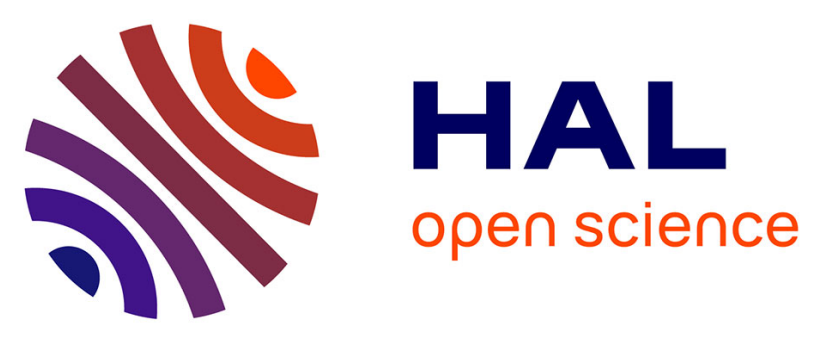

\title{
Undetectable levels of N6-methyl adenine in mouse DNA: Cloning and analysis of PRED28, a gene coding for a putative mammalian DNA adenine methyltransferase.
}

David Ratel, Jean-Luc Ravanat, Marie-Pierre Charles, Nadine Platet, Lionel Breuillaud, Joël Lunardi, François R. Berger, Didier Wion

\section{To cite this version:}

David Ratel, Jean-Luc Ravanat, Marie-Pierre Charles, Nadine Platet, Lionel Breuillaud, et al.. Undetectable levels of N6-methyl adenine in mouse DNA: Cloning and analysis of PRED28, a gene coding for a putative mammalian DNA adenine methyltransferase.. FEBS Letters, 2006, 580 (13), pp.3179-84. 10.1016/j.febslet.2006.04.074 . inserm-00390713

\section{HAL Id: inserm-00390713 https://www.hal.inserm.fr/inserm-00390713}

Submitted on 31 Jul 2009

HAL is a multi-disciplinary open access archive for the deposit and dissemination of scientific research documents, whether they are published or not. The documents may come from teaching and research institutions in France or abroad, or from public or private research centers.
L'archive ouverte pluridisciplinaire HAL, est destinée au dépôt et à la diffusion de documents scientifiques de niveau recherche, publiés ou non, émanant des établissements d'enseignement et de recherche français ou étrangers, des laboratoires publics ou privés. 


\section{Undetectable \\ levels of N6-methyl adenine in mouse DNA. \\ Cloning and analysis of PRED28, a gene coding for a putative mammalian DNA adenine methyltransferase.}

David Ratel, Jean-Luc Ravanato, Marie-Pierre Charles, Nadine Platet, Lionel Breuillaud, Joël Lunardi•, François Berger and Didier Wion*.

INSERM U318, UJFG, CHU Michallon, 38043 Grenoble, France. œ Laboratoire Lésions des Acides Nucléiques, LCIB (UMR-E CEA-UJF) DRFMC CEA Grenoble, 17 rue des Martyrs Grenoble, France, • Laboratoire de Biochimie et Génétique Moléculaire, CHU Grenoble 217X, 38041 Grenoble, Cedex, France.

*Corresponding author: INSERM U318, UJFG, CHU Michallon, 38043 Grenoble, France. didier.wion@ujf-grenoble.fr 


\begin{abstract}
Three methylated bases, 5-methylcytosine, N4-methylcytosine and N6-methyladenine (m6A), can be found in DNA. However, to date, only 5-methylcytosine has been detected in mammalian genomes. To re-investigate the presence of m6A in mammalian DNA, we used a highly sensitive method capable of detecting one N6-methyldeoxyadenosine per million nucleosides. Our results suggest that the total mouse genome contains, if any, less than $10^{3}$ m6A. Experiments were next performed on PRED28, a putative mammalian N6-DNA methyltransferase. The murine PRED28 encodes two alternatively spliced RNA. However, although recombinant PRED28 proteins are found in the nucleus, no evidence for an adeninemethyltransferase activity was detected.
\end{abstract}

Keywords: adenine methylation; DNA methylation; N6-methyladenine; Down syndrome. 


\section{Introduction}

In mammalian DNA, the crucial function of cytosine methylation in chromatin structure and gene functions has led to the consideration of 5-methylcytosine $(\mathrm{m} 5 \mathrm{C})$ as the fifth base of DNA [1,2]. In addition to $\mathrm{m} 5 \mathrm{C}$, there are two other known methylated bases, N6methyladenine (m6A) and N4-methylcytosine (m4C). However, m6A and m4C are generally considered to be specific to bacterial or protist DNA [3], and have not yet been identified in mammalian DNA. In prokaryotes, the function of $\mathrm{m} 4 \mathrm{C}$ and $\mathrm{m} 5 \mathrm{C}$ seems to be limited to restriction-modification systems [4], although $\mathrm{m} 5 \mathrm{C}$ is also part of the very short-patch repair system [5]. On the contrary, the biological role of m6A in bacteria is more widespread, and includes postreplicative DNA mismatch repair, chromosome compaction and regulation of gene expression [4]. Moreover, adenine methylation is essential for the virulence or viability of several pathogenic bacterial strains [6-8]. This suggests that bacterial N6-DNA methyltransferase is a potential target for the design of new antimicrobial agents [9]. The interest for this new generation of antibiotics highlights the necessity for determining the existence of N6-DNA methyltransferases in higher eukaryotes.

The current assumption that $\mathrm{m} 5 \mathrm{C}$ is the only methylated base present in animal DNA relies on experiments performed about thirty years ago with a detection limit of around $0.01 \%$ [10-12]. However, even if analytical methods failed to detect m6A in mammalian DNA, indirect evidence based on restriction enzyme analyses has suggested the presence of m6A in the mouse myogenic and the rat type 2 steroid $5 \alpha$-reductase genes $[13,14]$. Hence, current analytical methods are sufficient to detect m5C in mammalian DNA (approximately 1-6\%), but may be inadequate to detect the possible presence of a few hundred $\mathrm{m} 6 \mathrm{~A}$ in the $3.3 \times 10^{9}$ bases of the Homo sapiens genome [15]. This suggests that the methylation status of adenine in mammalian DNA could be similar to the situation encountered a few years ago with 
cytosine methylation in Drosophila melagonaster. Indeed, it had been well-accepted that DNA from Drosophila melagonaster was not methylated, a belief recently challenged by the presence of $\mathrm{m} 5 \mathrm{C}$ in this species [16]. In this regard, the recent characterization of a N6adenine DNA methyltransferase from wheat coleoptiles suggests the occurrence of adenine methylation in higher eukaryotes [17].

A prerequisite for the presence of m6A in mammalian DNA is the expression of a N6-DNA methyltransferase. In silico analyses of mouse and human genomes have identified the existence of the PRED28 gene that encodes a putative N6-DNA methyltransferase (http:/harvester.embl.de/harvester/Q9Y5/Q9Y5N5.htm; GenBank gene ID: 29104). This gene is located on human chromosome 21 or mouse chromosome 16 , two chromosomes syntenic for this region. This situation prompted us to re-examine the methylation status of adenine in mammalian DNA. 


\section{Material and Methods.}

\section{Bacterial strains.}

E. coli TOP10 (Invitrogen) was used for transformation procedures and maintenance of plasmids. E. coli GM $272\left(\mathrm{dam}^{-}, \mathrm{dcm}^{-}, h s d \mathrm{~S}^{-}\right)$[18] was used for expression studies. This strain has mutations in genes encoding the adenine DNA methyltransferases and is therefore expected to have very little m6A in its DNA.

\section{DNA purification and analys is.}

DNA analysis. Genomic DNA was extracted using the Genomic DNA buffer set and Qiagen Genomic Tip from Qiagen (Qiagen, Courtaboeuf, France). Human placental mitochondria were purified as described [19]. Mitochondrial DNA was extracted using the QIAamp DNA kit from Qiagen (Qiagen, Courtaboeuf, France). Subsequently, genomic or mitochondrial DNA was incubated with a mixture of endo- and exonucleases, and alkaline phosphatase that quantitatively liberate N6-methyldeoxyadenosine (MedAdo) [20]. This was demonstrated using plasmid DNA that contained a known amount of MedAdo. A HPLC-electrospray ionization tandem mass spectrometry (HPLC-MS/MS) method has been developed for the detection of MedAdo, as previously described for the measurement of oxidized nucleosides [21,22]. The HPLC-MS/MS system used for the detection of MedAdo has been previously described [23]. The limits of sensitivity $(S / N=3)$ for the assay were close to $20 \mathrm{fmol}$ of injected MedAdo (corresponding to a concentration of $0.5 \mathrm{nM}$ ). Quantification was performed by external calibration, and the amount of DNA was determined by UV absorption using the peak of deoxyguanosine [22].

\section{RNA purification and reverse transcription (RT)-PCR.}


Total RNA extraction and RT-PCR were performed using the Rneasy and Qiagen OneStep RT-PCR kits (Qiagen, Courtaboeuf, France). Oligonucleotide primers were designed based on the mouse PRED28 cDNA sequence available in the GenBank ${ }^{\text {TM }}$ data base under accession AY456393. The oligonucleotides used were PRED1a 5'GTGCGTACTCAACGCCCGCCCATAGG-3' (forward) and PRED1b 5'GCTGCCGGCAGCTCTTGTTTACTTCTGTGG (reverse). Genomic DNA contamination was controlled by PCR of non-reverse transcribed RNA.

\section{Cloning of PRED28 splice va riants.}

The coding regions of PRED28 $\alpha$ and PRED28 $\beta$ were amplified by RT-PCR from embryonic mouse brain mRNA and cloned into pcDNA3.1/V5His-TOPO (Invitrogen) to generate pcDNA3/PRED28 $\alpha$ and pcDNA3/PRED28 $\beta$. Primers used for PRED28 $\alpha$ amplification are 5'- GCGGAAGGGAAAAGATGGCGGCGCC-3' (forward) and 5'GAGGGACTTGCTGAACCTGAGGACTGACAGG-3' (reverse). Primers used for PRED28 $\beta$ are 5'- GCGGAAGGGAAAAGATGGCGGCGCC-3' (forward) and 5'CAATTGTTTTAAAGATTTCCTCTCAG-3' (reverse). The cDNA sequence of PRED28 $\alpha$ corresponds to the sequence of the Mus musculus N6-DNA methyltransferase mRNA in GenBank under accession AY456393, whereas the cDNA sequence of PRED28 $\beta$ corresponds to a new transcript variant deposited under accession AY536887. The full-length coding regions of pcDNA3/PRED28 $\alpha$ and pcDNA3/PRED28 $\beta$ were amplified with the primers 5'GGGGTACCGAGCTCGGATCCACTAG-3' (forward) and 'CACGGGGGATCCGCAAACAACAGATGGCTGGCAAC-3' (reverse) and subcloned in the BamHI site of the eukaryotic expression vector pcDNA4/TO (Invitrogen) to generate pcDNA4/PRED28 $\alpha$ and pcDNA4/PRED28 $\beta$. To express PRED28 isoforms in E. coli, the coding regions of the two isoforms of PRED28 were amplified and cloned under the control 
of the $\operatorname{araBAD}$ promoter in the bacterial expression vector pBAD-TOPO (Invitrogen) to generate $\mathrm{pBAD} / \mathrm{PRED} 28 \alpha$ and $\mathrm{pBAD} / \mathrm{PRED} 28 \beta$. The primers used for PRED28 $\alpha$ amplification were 5'-GCGGCGCCGAGTGTCCCCACGCCG-3' (forward) and 5'GAGGAATAATAAATGGCGGCGCCGAGTGTCCCCACGCCG-3' (reverse), and the primers used for PRED28 $\beta$ are 5'-GCGGCGCCGAGTGTCCCCACGCCG-3' (forward) and 5'-TAATAAATGGCGGCGCCGAGTGTCCCCACG-3' (reverse). All the resulting recombinant proteins contain a C-terminal V5 epitope tag and a C-terminal $6 \mathrm{x}$ His tag. All the constructs were verified by DNA sequencing.

\section{Cell culture and transfection.}

C2C12 cells were grown to approximately $80 \%$ confluence, and transfection was performed by incubating $\mathrm{C} 2 \mathrm{C} 12$ cells with either pcDNA4/PRED28 $\alpha$ or pcDNA4/PRED28 $\beta$ vector using the Lipofectamine $2000^{\mathrm{TM}}$ reagent according to the manufacturer's instructions (Invitrogen). For selection of stable recombinant clones, zeocin $(100 \mu \mathrm{g} / \mathrm{ml})$ was added $72 \mathrm{hr}$ after transfection. Expression was verified by immunofluorescence staining and western blot using a V5 antibody (Invitrogen).

\section{Bacterial expression of recombinant PRED28.}

For the bacterial expression of recombinant proteins, E. coli GM272 clones harboring either $\mathrm{pBAD} / \mathrm{PRED} 28 \alpha$ or $\mathrm{pBAD} / \mathrm{PRED} 28 \beta$ were grown at $37^{\circ} \mathrm{C}$ in $\mathrm{LB}$ broth containing Amp to an O.D.600 of $m 0.25$. At this point the cultures were split, and L-arabinose $(0.1 \%$ final concentration) was added to one of the cultures to induce protein production. After one hour, the bacteria were centrifuged and processed for either DNA extraction or for western blot analysis. For western blot analysis, cell pellets were resuspended and lysed in CelLytic ${ }^{\mathrm{TM}}$ buffer (Sigma). Then, cell lysates were centrifugated at $18000 \mathrm{x}$ g for 15 minutes to pellet the 
insoluble material. Western blot analyses were performed on both the supernatant and insoluble fractions using a V5 antibody (Invitrogen). For DNA analysis, DNA was extracted using the DNA genomic buffer set from Qiagen according to the manufacturer's instructions. 


\section{Results}

\section{Determination of m6A content in mammalian and mitochondrial DNA.}

Previous base analyses of mammalian DNA have failed to detect the presence of m6A. However, these analyses were performed over twenty years ago with a detection threshold around $0.01 \%$. Therefore, in an attempt to re-examine the problem of adenine methylation in mammalian DNA, we have developed an extremely sensitive assay for MedAdo with a detection threshold of one MedAdo per $10^{6}$ nucleosides. However, even using this sensitive assay we were unable to detect adenine methylation in the nuclear DNA of several mouse tissues (Table 1). According to the size of the mouse genome $(2.5 \mathrm{~Gb})$, these results suggest that the total mouse genome contains less than $2.5 \times 10^{3} \mathrm{~m} 6 \mathrm{~A}$. In addition, since it has been suggested that mitochondria could be the degenerate descendants of endosymbiotic bacteria, and since bacterial DNA is known to contain m6A, mitochondrial DNA from human placenta was also included in this study. In contrast to bacterial DNA, which contains MedAdo, no MedAdo was detected in mitochondrial DNA (Table 1).

\section{Tissue expression profile of PRED28/N6AM1, a putative N6-DNA methyltransferase.}

The presence of less than $10^{3} \mathrm{~m} 6 \mathrm{~A}$ in the whole mouse genome could be biologically significant if adenine methylation occurs in rare specific gene regulatory elements. However, it is difficult to demonstrate the existence of a base which is below the detection limits of current analytical methods. This difficulty can be circumvented if we consider that a prerequisite for the presence of $\mathrm{m} 6 \mathrm{~A}$ is the existence of a gene coding for a N6-DNA methyltransferase. Analysis of the human and mouse genomes reveals the presence of PRED28/N6AM1 on human chromosome 21, or on mouse chromosome 16, which was annotated as a putative N6-DNA methyltransferase on the basis of in silico analysis (GenBank 
accession AY456393). In order to determine the tissue expression profile of PRED28, oligonucleotide primers for the mouse PRED28 cDNA sequence deposited in GenBank (accession AY456393) were used to amplify PRED28 mRNA. RT-PCR analysis of mRNA derived from several mouse tissues demonstrates that the PRED28 gene is expressed in all the tissues examined (Fig. 1). Interestingly, two PRED28 isoforms, named PRED $\alpha$ and PRED $\beta$, were detected in mouse tissues. The longer PRED28 isoform (PRED28 $\alpha$ ) is dominant in adult tissues.

\section{Cloning and Characterization of PRED28 isoforms.}

To characterize these two mRNAs, molecular cloning and DNA sequencing of the corresponding PRED28 $\alpha$ and PRED28 $\beta$ cDNA were performed. Nucleotide sequences confirm that the PRED28 $\alpha$ sequence corresponded to the sequence of the Mus musculus N6DNA methyltransferase mRNA already deposited in GenBank under accession AY456393, which encodes for a $23 \mathrm{kDa}$ putative protein (214 amino acids). In contrast, the PRED28 $\beta$ sequence corresponded to a new transcript variant that we deposited under accession AY536887. Interestingly, this alternative splicing introduces a frame shift that generates a stop codon soon after the beginning of exon VI. Thus, PRED $\beta$ cDNA encodes a putative protein of $14.7 \mathrm{kDa}$ (138 amino acids) (Fig. 2).

\section{Subcellular Localization of PRED28 isoforms.}

To gain insight into the biological function of the PRED28 protein, we analyzed the subcellular localization of the two PRED28 isoforms. For this purpose, full-length coding sequences corresponding to PRED28 $\alpha$ and PRED28 $\beta$ were cloned into the eukaryotic expression vector pcDNA4/TO. Then, $\mathrm{C} 2 \mathrm{C} 12$ cells were transfected with either pcDNA4/PRED28 $\alpha$ or pcDNA4/PRED28 $\beta$. Two stable cell lines expressing either 
PRED28 $\alpha$ (C2C12-Pred $\alpha)$ or PRED28 $\beta$ (C2C12-Pred $\beta)$ were generated. Results presented in Fig. 3 show that recomb inant proteins localized mainly in the nucleus.

\section{PRED28 expression in E. coli and C2C12 cells.}

To investigate the ability of PRED28 to methylate adenine residues in DNA, PRED28 $\alpha$ and PRED28 $\beta$ were expressed in the E. coli GM272 strain. GM272 is a $h s d r^{-}$, dam ${ }^{-}$, dcm $^{-}$mutant [18]. Thus, GM272 DNA contains low levels of m6A and is therefore a useful tool to determine if PRED28 production can induce methylation of DNA. DNA fragments encoding either PRED28 $\alpha$ or PRED28 $\beta$ were placed under the control of the araBAD promoter in the vector $\mathrm{pBAD}-\mathrm{TOPO}$ to generate $\mathrm{pBAD} / \mathrm{PRED} 28 \alpha$ or $\mathrm{pBAD} / \mathrm{PRED} 28 \beta$ expression vectors. Upon exposure of recombinant GM272 to $0.1 \%$ arabinose for 1 hour, immunoblotting of cell lysates reveals a protein with a molecular mass corresponding to the PRED28 isoforms (data not shown). Analysis of the supernatant and pellet of lysed cells shows that following arabinose induction, most of the synthesized protein is found in the soluble fraction (data not shown). However, this expression does not increase the basal level of MedAdo found in GM272 (Table 1). This residual methyl transferase activity may be due to rare dam+ revertants in the cell culture, since this allele reverts at a very low frequency (M. Marinus, personal communication). Likewise, no MedAdo can be detected in the genomic DNA of mammalian $\mathrm{C} 2 \mathrm{C} 12$ cells that are stably transfected with expression vectors encoding either PRED28 $\alpha$ or PRED28 $\beta$ (Table 1). Therefore, we conclude that under our assays conditions, PRED28 has no detectable adenine DNA methyltransferase activity. 


\section{Discussion}

In order to re-investigate the adenine methylation status of mammalian DNA, we developed an extremely sensitive assay for MedAdo detection. Using this assay, which is over 100 times more sensitive than previous methods, we were unable to identify adenine methylation in the nuclear DNA of several mouse tissues or in human mitochondrial DNA. Hence, if adenine methylation occurs, it would only comprise a few hundred adenines. Alternatively, adenine methylation could be restricted to a minor population of cells (i.e. stem cells), or may occur during a brief period of the cell cycle. Moreover, it should be noted that the presence of a few m6A in DNA may be critical if they are used to control the expression of a small subset of transcription factors or miRNAs. In this regard, it is noteworthy that the artificial methylation of adenine in several eukaryotic or viral promoters alters their activity [24-27]. Moreover, the addition of MedAdo to cell culture medium has been reported to induce cell differentiation $[23,28]$.

An alternative way to determine the presence of m6A in mammalian genomes is to investigate the existence of a N6-DNA methyltransferase in mammalian cells. On the basis of bioinformatic analysis, a gene named PRED28, already annotated as coding for a putative N6DNA methyltransferase, has been found in murine and human genomes. In humans, two mRNA species resulting from the alternative splicing of exon IV have been described (NM_013240 and NM_182749) (Fig. 2). Removal of exon IV would be critical for the enzymatic activity of the protein since it codes for the NPPY motif characteristic of N6-DNA methyltransferases [29] (Fig. 2). This would suggest that the shorter human variant, named PRED $\beta$, should be devoid of enzymatic activity. Our results show that in mice, PRED $\beta$ is generated by removal of exon $\mathrm{V}$ instead of exon IV (Fig 2). Therefore, this alternative splicing does not delete the NPPY motif, but results in a frame shift and appearance of a premature stop codon in the new reading frame. Hence, the removal of the NPPY site in the 
human gene and the generation of a frame shift introducing a premature stop codon in the mouse gene could represent two alternative methods to generate these is oforms. This could be an additional illustration of the role played by molecular tinkering during the course of evolution.

Although devoid of a nuclear localization signal (NLS), both PRED isoforms are predominantly localized to the nucleus when expressed in $\mathrm{C} 2 \mathrm{C} 12$ cells (Fig. 3). A likely explanation for this nuclear localization is the small size of PRED proteins. The estimated molecular weights (MW) of PRED $\alpha$ and PRED $\beta$ are 23 and $14.7 \mathrm{kDa}$, respectively. The addition of the V5 epitope increases the MW of the fusion proteins by $4.9 \mathrm{kDa}$. The nuclear pore complex (NPC) allows slow diffusion of proteins between 10-20 kDa [30]. Therefore, the nuclear entry of the PRED proteins could be caused by passive diffusion through the NPC. Interactions of these two PRED isoforms with nuclear proteins or nucleic acids could limit their export from the nucleus. This could explain their preferential localization in the nucleus Even though a N6-DNA methyltransferase is predicted to display nuclear localisation, expression of PRED28 isoforms in bacteria or in mammalian cells failed to demonstrate any adenine DNA methyltransferase activity. A possible explanation for the lack of N6-DNA methyltransferase activities of PRED proteins in our methylation assays could be the absence of unidentified cofactor(s) required for enzymatic activity. Likewise, the tag used to identify the recombinant PRED proteins may interfere with proper activity. Alternatively, the annotation of PRED28 as a putative N6-DNA methyltransferase could have been erron eous. Indeed, the NPPY motif characteristic of N6-DNA methyltransferases was recently found to be shared by HemK proteins. The HemK protein was initially misidentified and annotated as a component of the heme biosynthetic pathway [31]. However, it is now recognized as a bacterial N5-glutamine methyltransferase [32]. Therefore, the possibility that PRED28 is an uncharacterized mammalian N5-glutamine methyltransferase should be considered. This point 
warrants further investigation because the human PRED28 gene is localized on chromosome 21, and it may have a possible contribution to the pathology of Down syndrome.

On the basis of computer analysis, open reading frames distinct from PRED28 which code for several other putative N6-DNA methyltransferases have been detected in eukaryotic genomes [33]. This raises the possibility that in higher eukaryotes, proteins other than PRED28 could be involved in the methylation of a small number of adenine residues, a point of crucial concern if N6-DNA methyltransferase inhibitors are to be used as antibiotics [9,34].

Acknowledgements: We thank Dr M Marinus for the gift of the E. coli GM272 strain and helpful discussions. We are grateful to Marie Ratel for critical reading of the manuscript. This work was supported by the Fondation Jérôme Lejeune and the Ligue Nationale contre le Cancer.

\section{References.}

[1] Doerfler, W. (2005) On the biological significance of DNA methylation. Biochemistry (Mosc) 70, 505-524.

[2] Vanyushin, B.F. (2005) Enzymatic DNA methylation is an epigenetic control for genetic functions of the cell. Biochemistry (Mosc) 70, 488-499.

[3] Hattman, S. (2005) DNA-[adenine] methylation in lower eukaryotes. Biochemistry (Mosc) $70,550-558$.

[4] Wion, D. and Casadesus, J. (2006) N(6)-methyl-adenine: an epigenetic signal for DNAprotein interactions. Nat. Rev. Microbiol. 4, 183-192. 
[5] Bhagwat, A.S. and Lieb, M. (2002) Cooperation and competition in mismatch repair: very short-patch repair and methyl-directed mismatch repair in Escherichia coli. Mol. Microbiol. 44, 1421-1428.

[6] Low, D.A., Weyand, N.J., and Mahan, M.J. (2001) Roles of DNA adenine methylation in regulating bacterial gene expression and virulence. Infect. Immun. 69, 7197-7204.

[7] Garcia-Del Portillo, F., Pucciarelli, M.G. and Casadesus, J. (1999) DNA adenine methylase mutants of Salmonella typhimurium show defects in protein secretion, cell invasion, and M cell cyto toxicity. Proc. Natl. Acad. Sci. US A 96, 11578-11583.

[8] Heithoff, D.M., Sinsheimer, R.L., Low, D.A. and Mahan, M.J. (1999) An essential role for DNA ad enine methylation in bacterial virulence. Science 284, 967-970.

[9] Mashhoon, N., Carroll, M., Pruss, C., Eberhard, J., Ishikawa, S., Estabrook, R.A., and Reich, N. (2004) Functional characterization of Escherichia coli DNA adenine methyltransferase, a novel target for antibiotics. J. Biol. Chem. 279, 52075-52081.

[10] Lawley, P.D., Crathorn, A.R., Shah, S.A., and Smith, B.A. (1972) Biomethylation of deoxyribonucleic acid in cultured human tumour cells (HeLa). Methylated bases other than 5-methylcytosine not detected. Biochem. J. 128, 133-138.

[11] Gunthert, U., Schweiger, M., Stupp, M. and Doerfler, W. (1976) DNA methylation in adenovirus, adenovirus-transformed cells, and host cells. Proc. Natl. Acad. Sci. U S A 73, 3923-3927.

[12] Vanyushin, B.F., Tkacheva, S.G. and Belozersky, A.N. (1970) Rare bases in animal DNA. Nature 225, 948-949.

[13] Reyes, E.M., Camacho-Arroyo, I., Nava, G. and Cerbon, M.A. (1997) Differential methylation in stero id 5 alpha-reductase isozyme genes in epididymis, testis, and liver of the adult rat. J. Androl. 18, 372-377. 
[14] Kay, P.H., Pereira, E., Marlow, S.A., Turbett, G., Mitchell, C.A., Jacobsen, P.F., Holliday, R., and Papadimitriou, J.M. (1994) Evidence for adenine methylation with in the mouse myogenic gene Myo-D1. Gene 151, 89-95.

[15] Ratel, D., Ravanat, J.L., Berger, F., and Wion, D. (2006) N6-methyladen ine: the other methylated base of DNA. Bioessays 28, 309-315.

[16] Gowher, H., Leismann, O. and Jeltsch, A. (2000) DNA of Drosophila melanogaster contains 5-methylcytosine. Embo J. 19, 6918-6923.

[17] Fedoreyeva, L.I. and Vanyushin, B.F. (2002) N(6)-Adenine DNA-methyltransferase in wheat seedlings. FEBS Lett. 514, 305-308.

[18] Palmer, B.R. and Marinus, M.G. (1994) The dam and dem strains of Escherichia coli-a review. Gene 143, 1-12.

[19] Dani, S.U., Gomes-Ruiz, A.C. and Dani, M.A. (2003) Evaluation of a method for high yield purification of largely intact mitochondrial DNA from human placentae. Genet. Mol. Res. 2, 178-184.

[20] Ravanat, J.L., Douki, T., Duez, P., Gremaud, E., Herbert, K., Hofer, T., Lasserre, L., Saint-Pierre, C., Favier, A. and Cadet, J. (2002) Cellular background level of 8-oxo7,8-dihydro-2'-deoxyguanosine: an isotope based method to evaluate artefactual oxidation of DNA during its extraction and subsequent work-up. Carcinogenesis 23, 1911-1918.

[21] Ravanat, J.L., Duretz, B., Guiller, A., Douki, T. and Cadet, J. (1998) Isotope dilution high-performance liquid chromatography-electrospray tandem mass spectrometry assay for the measurement of 8-oxo-7,8-dihydro-2'-deoxyguanosine in biological samples. J. Chromatogr. B. Biomed. Sci. Appl. 715, 349-356.

[22] Frelon, S., Douki, T., Ravanat, J.L., Pouget, J. P., Tornabene, C. and Cadet, J. (2000) High-performance liquid chromatography--tandem mass spectrometry measurement of 
radiation-induced base damage to isolated and cellular DNA. Chem. Res. Toxicol. 13, 1002-1010.

[23] Charles, M. P., Ravanat, J. L., Adamski, D., D'Orazi, G., Cadet, J., Favier, A., Berger, F. and Wion, D. (2004) N(6)-Methyldeoxyadenosine, a nucleoside commonly found in prokaryotes, induces $\mathrm{C} 2 \mathrm{C} 12$ myogenic differentiation. Biochem. Biophys. Res. Commun. 314, 476-482.

[24] Truss, M., Bartsch, J., Chalepakis, G., and Beato, M. (1992) Artificial steroid hormone response element generated by dam-methylation. Nucleic Acids Res. 20, 1483-1486.

[25] Knebel, D. and Doerfler, W. (1986) N6-methyldeoxyadenosine residues at specific sites decrease the activity of the E1A promoter of adenovirus type 12 DNA. J. Mol. Biol. $189,371-375$.

[26] Graham, M.W. and Larkin, P.J. (1995) Adenine methylation at dam sites increases transient gene expression in plant cells. Transgenic Res. 4, 324-331.

[27] Tronche, F., Rollier, A., Bach, I., Weiss, M.C., and Yaniv, M. (1989 The rat albumin promoter: cooperation with upstream elements is required when binding of APF/HNF1 to the proximal element is partially impaired by mutation or bacterial methylation. Mol. Cell. Biol. 9, 4759-4766.

[28] Ratel, D., Boisseau, S., Davidson, S. M., Ballester, B., Mathieu, J., Morange, M., Adamski, D., Berger, F., Benabid, A. L. and Wion, D. (2001) The bacterial nucleoside $\mathrm{N}(6)$-methyldeoxyadenosine induces the differentiation of mammalian tumor cells. Biochem. Biophys. Res. Commun. 285, 800-805.

[29] Jeltsch, A., Christ, F., Fatemi, M. and Roth, M. (1999) On the substrate specificity of DNA methyltransferases. Adenine-N6 DNA methyltransferases also modify cytosine residues at position N4. J. Biol. Chem. 274, 19538- 19544. 
[30] Pouton, C.W. (1998) Nuclear import of polypeptides, polynucleotides and supramolecular complexes. Adv. Drug Deliv. Rev. 34, 51-64.

[31] Nakayashiki, T., Nishimura, K. and Inokuchi, H. (1995) Cloning and sequencing of a previously unidentified gene that is involved in the biosynthesis of heme in Escherichia coli. Gene 153, 67-70.

[32] Nakahigashi, K., Kubo, N., Narita, S., Shimaoka, T., Goto, S., Oshima, T., Mori, H., Maeda, M., Wada, C. and Inokuchi, H. (2002) HemK, a class of protein methyl transferase with similarity to DNA methyl transferases, methylates polypeptide chain release factors, and hemK knockout induces defects in translational termination. Proc. Natl. Acad. Sci. US A 99, 1473-1478.

[33] Shorning, B.Y. and Vanyushin, B. F. (2001) Putative DNA-(amino)methyltransferases in eucaryotes. Biochemistry (Mosc) 66, 753-762.

[34] Wahnon, D.C., Shier, V.K. and Benkovic S. J. (2001) Mechanism-based inhibition of an essential bacterial adenine DNA methyltransferase: rationally designed antibiotics. J. Am. Chem. Soc. 123, 976-977. 


\section{Legends to figures.}

Fig. 1. RT-PCR analysis of the tissue specific (A) and developmental expression (B) of PRED28 in mouse.

Although both PRED $\alpha$ and $\beta$ are ubiquitous in all tissues examined, PRED $\alpha$ is expressed at higher levels than PRED $\beta$ in adult tissues.

Fig. 2. Genomic orga nization and structure of alte rnatively splic ed transcripts of mouse and human PRED28.

The splicing of exon $\mathrm{V}$ in the mouse PRED28 results in a frame shift. The two resulting alternative amino-acid sequences encoded by the mouse exon VI are shown. GeneBank accession numbers are included.

Fig. 3. Expression of cloned PRED28 $\alpha$ or PRED28 $\beta$ cDNA in C2C12 cells.

The predominant nuclear location of recombinant PRED28 proteins was demonstrated by immunofluorescence staining of $\mathrm{C} 2 \mathrm{C} 12$ cells transfected with either pcDNA4/PRED28 $\alpha$ or pcDNA4/PRED28 $\beta$ expression vectors. The PRED28 isoforms are labelled in green with an anti-V5 antibody (Invitrogen) and DNA is labelled in red by propidium iodide.

Table 1. Content of MedAdo in the DNA of different mouse tissues or cells. 


\begin{tabular}{cc}
\hline Source of DNA & MedAdo/10 \\
\hline heart & \\
muscle & $<1$ \\
liver & $<1$ \\
brain & $<1$ \\
testis & $<1$ \\
brain & $<1$ \\
mitochondria & $<1$ \\
C2C12 & $<1$ \\
C2C12-Pred $\alpha$ & $<1$ \\
C2C12-Pred $\beta$ & $<1$ \\
E. coli GM272-PRED $\alpha$ non-induced $(\mathrm{n}=3)$ & $38.4 \pm 10.5$ \\
E. coli GM272-PRED $\alpha$ induced $(\mathrm{n}=3)$ & $35.1 \pm 9.6$ \\
E. coli GM272-PRED $\beta$ non-induced $(\mathrm{n}=2)$ & $44.1 \pm 3.9$ \\
E. coli GM272-PRED $\beta$ induced $(\mathrm{n}=3)$ & $35.2 \pm 4.2$ \\
\end{tabular}




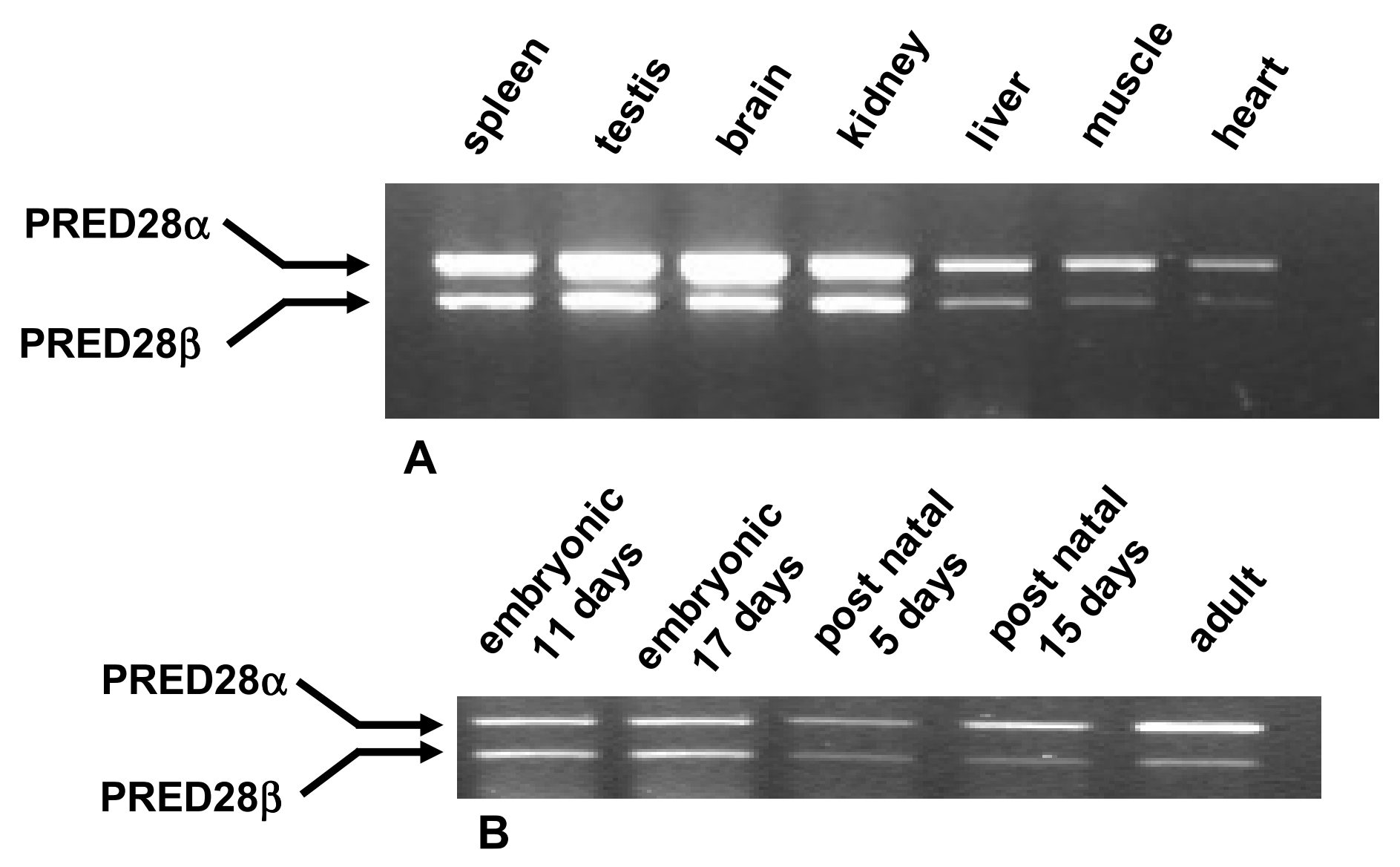



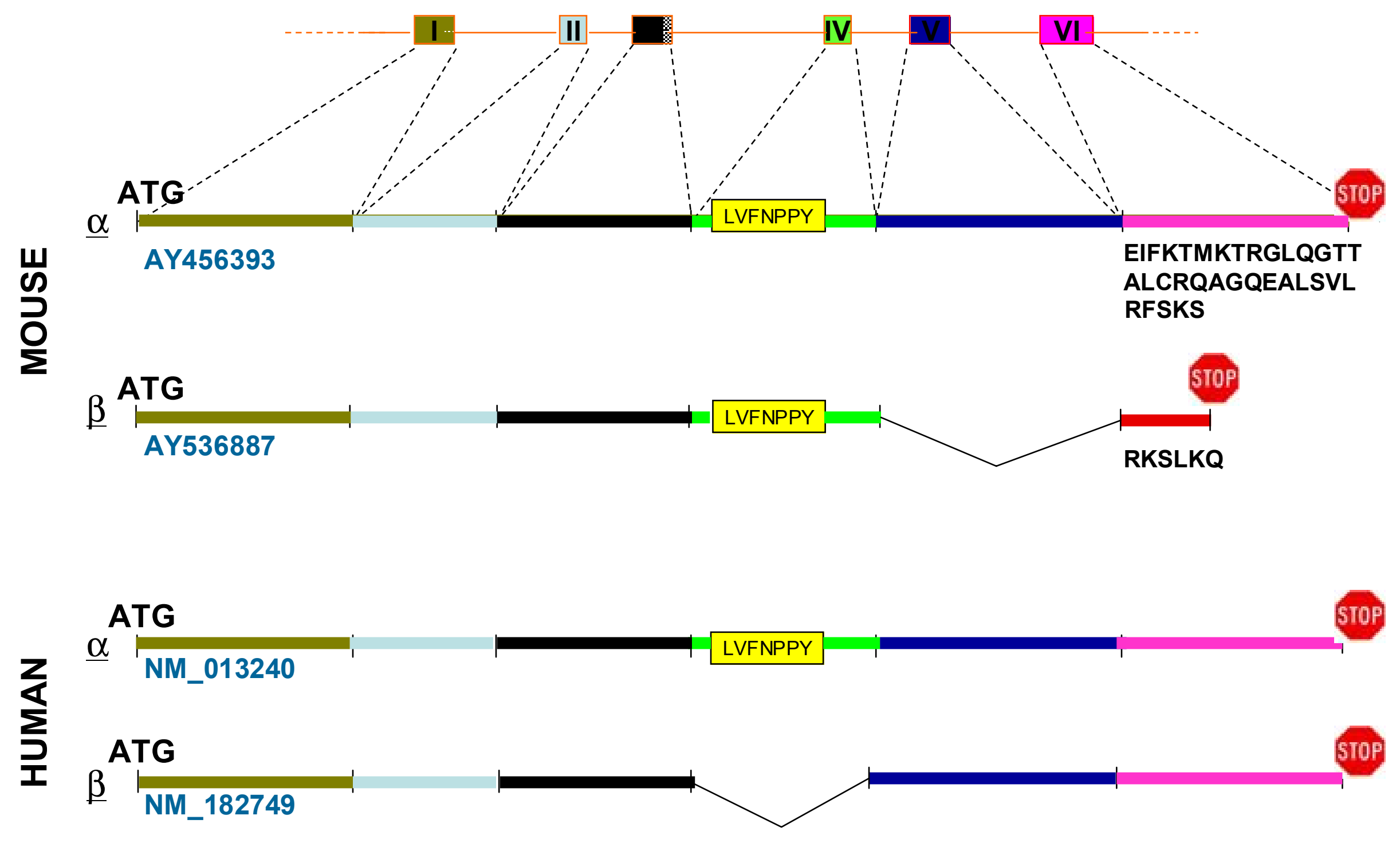
Control
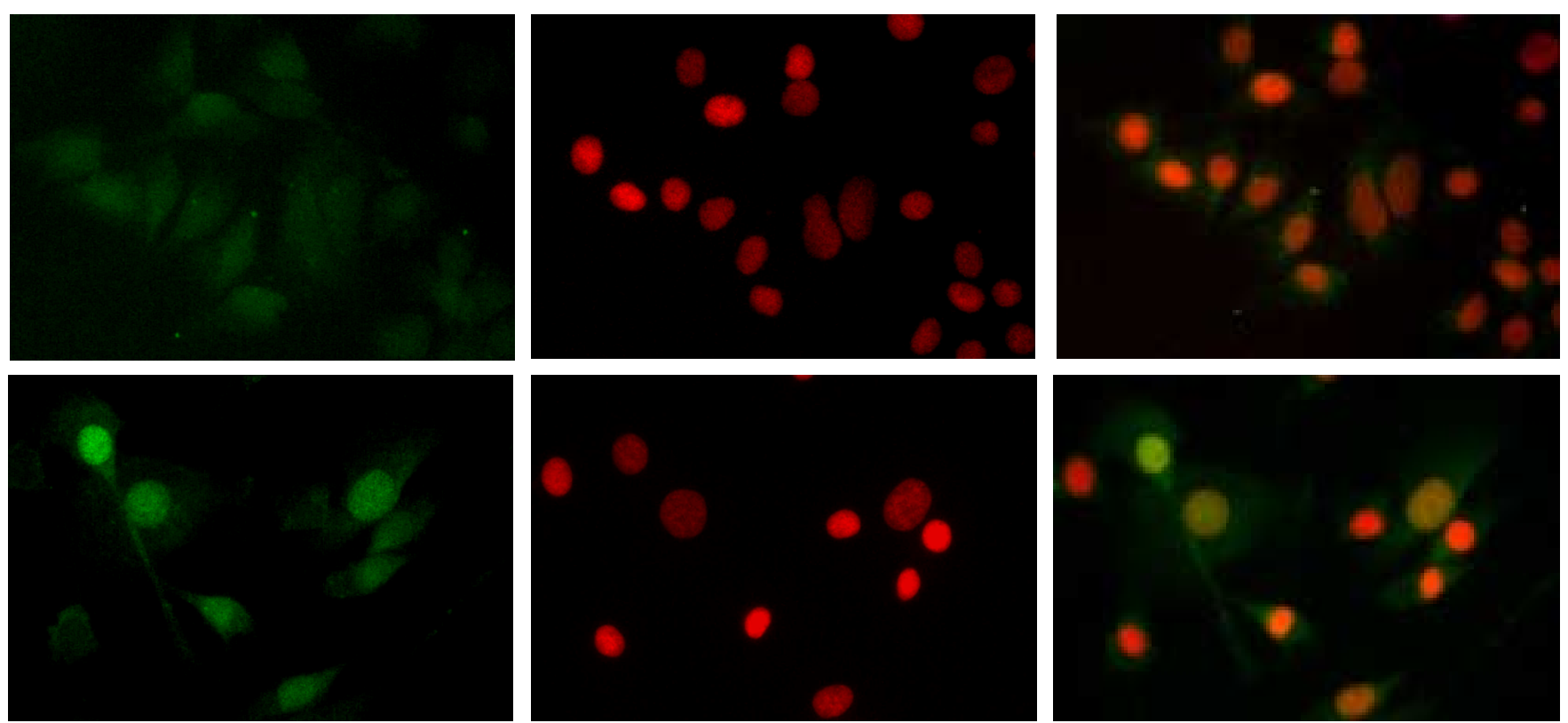

PRED28- $\beta$

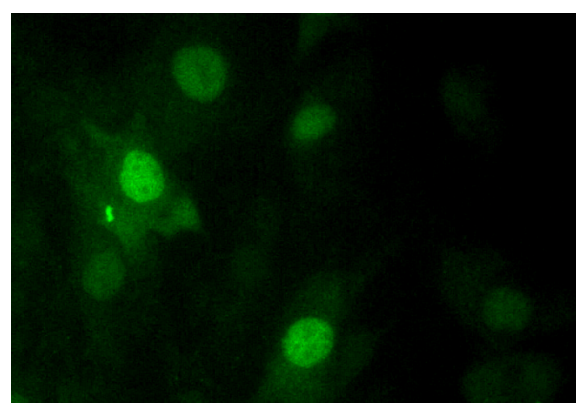

Anti-V5

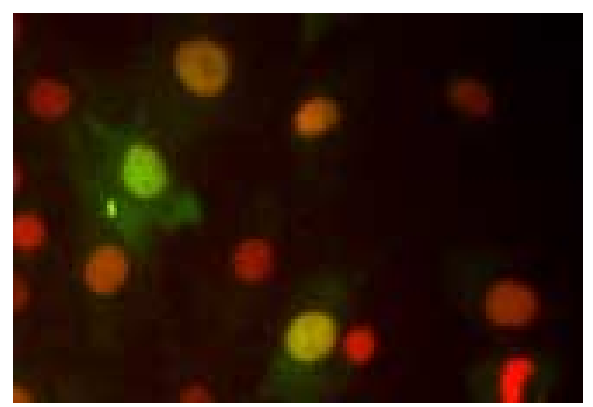

propidium iodide

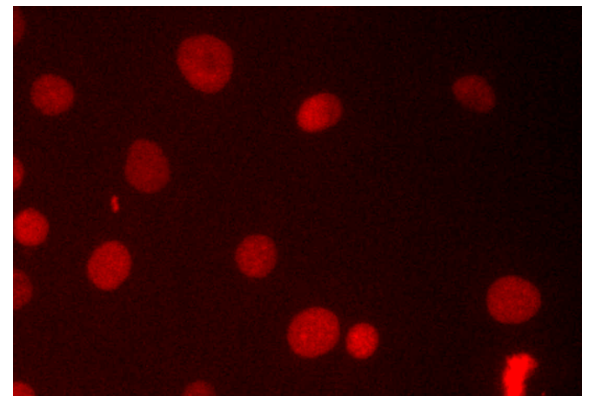

overlay 